\title{
Simulating the impact of Grain-for-Green Programme on ecosystem services trade-offs in North-western Yunnan, China
}

Jian Penga, b*, Xiaoxu Hu ${ }^{a}$, Xiaoyu Wang ${ }^{a}$ b, Jeroen Meersmans ${ }^{c}$, Yanxu Liu ${ }^{d}$, Sijing

Qiu $^{\mathbf{a}}$

a Laboratory for Earth Surface Processes, Ministry of Education, College of Urban and Environmental Sciences, Peking University, Beijing 100871, China

b Key Laboratory for Environmental and Urban Sciences, School of Urban Planning and Design, Shenzhen Graduate School, Peking University, Shenzhen 518055, Chinac, Cranfield Soil and Agrifood Institute, School of Water, Energy and Environment, Cranfield University, Cranfield, MK43 OAL, United Kingdom d State Key Laboratory of Earth Surface Processes and Resource Ecology, Faculty of Geographical Science, Beijing Normal University, Beijing 100875, China

\begin{abstract}
One of the main manifestations of the Grain-for-Green Programme (GFGP) is land use change, which will affect the trade-off of ecosystem services. Since the implementation of the GFGP in Dali Autonomous Prefecture in 2000, land use/cover has undergone dramatic changes. This study used the CLUE-S model to simulate land use change in 2030, and explored the spatial pattern and relationship of different ecosystem services under the four scenarios of GFGP. The results show that, GFGP can help to improve indirect services of ecosystems, such as carbon storage and soil conservation. However, direct services of the ecosystem will decline, such as food production and water yield. Compared with 2010, the overall supply level of the four ecosystem services is the most balanced in the moderate GFGP scenario. In this
\end{abstract}

\section{${ }^{*}$ Corresponding author}

E-mail address: jianpeng@urban.pku.edu.cn (J. Peng). 
scenario, total grain production decreased by 179,000 tons and water yield decreased by 57 million cubic meters. Carbon storage and soil conservation continued to grow, increasing by 21.86 million tons and 17.89 million tons, respectively. The changes of ecosystem services in the strong GFGP scenario are extreme. The increases in carbon storage and soil conservation are at the expense of a significant reduction in food production and water yield. It can be concluded that GFGP may lead to intensifying ecosystem services trade-offs. Through comparing the changes of ecosystem services under different GFGP scenarios, it is found that the implementation intensity of GFGP should be deeply concerned.

Key Words: Grain-for-Green Programme; Ecosystem services trade-offs; Scenario analysis; Northwestern Yunnan

\section{Introduction}

Ecosystems and related environment processes across multiple scales are the foundations on which humans rely for their existence. Costanza et al. (1997) defined ecosystem services as the benefits people obtain directly or indirectly from ecosystems. Ecosystems can provide multiple services to humans at the same time, while some ecosystem services can not be consumed simultaneously. There is a close but complex relationship among different types of ecosystem services. Accurately revealing the relationship between ecosystem services helps to effectively utilize the ecosystem. Ecosystem service trade-offs can be characterized as an increase of specific ecosystem services at the expense of another ecosystem services. It is the most representative relationship between ecosystem services and has important research significance (Rodríguez et al. 2006). The trade-off between ecosystem services can be strongly influenced by human activities. For example, changes in the type, intensity, and scale 
of land use may result in the changes of ecosystem services (Tolessa et al., 2017). Ecological engineering is often accompanied by a shift of land use patterns. Studies have shown that in the implementation of ecological engineering, if the trade-off relationship between different types of ecosystem services is not paid attention to, it is difficult to maximize ecological benefits and even cause a series of ecological problems (Divinsky et al., 2017; Geneletti, 2013; Goldstein et al., 2012).

The identification of ecosystem services trade-offs can be conducted through the quantitative index method or comprehensive model method with specific spatiotemporal scales (Konarska et al., 2004; Lafortezza \& Chen, 2016; Yi et al., 2018). For a specific region, scenario analysis and multi-objective analysis become effective means of balancing ecosystem services (Hu et al., 2015; Li et al., 2017; Sandhu et al., 2018). Through establishing a future scenario based on ecosystem protection or socioeconomic development or both, comprehensive analysis of ecosystem change trends will help to find the best way to optimize ecosystem services (Hao and Yu, 2018; Scholte et al., 2018). However, to reduce the uncertainty in simulating ecosystem services, natural geographical, socio-economic, and policy factors should be considered as more as possible (Costanza et al., 2017; Hu et al., 2018; Liu et al., 2017).

In the context of the transformation of human-land relationship, land use change scenario analysis has become an important means of quantifying ecosystem services response to land use policy (Xu et al., 2019; Halecki et al., 2018; Kerschbaumer et al., 2015). The land use change scenario analysis determines the different land use needs according to the driving factors of land use patterns, and regards it as a demanding for different land use types in the future. This approach can not only determine the extent to which specific ecosystem services can be maximized in the future, but can also be used to identify potential ecosystem services trade-offs across different spatial-temporal 
scales. Commonly used land use simulation models include the following four types: (i) Conversion of Land Use and its Effects at Small Region Extent (CLUE-S) model based on empirical statistics, (ii) Agent-Based Model (ABM) based on multiple agents, (iii) Cellular Automata (CA) model based on neighborhood relationship analysis, and (iv) Dynamics of Land System (DLS) model based on structural changes in land systems and succession of spatial pattern analysis. In various case studies, ecosystem services trade-offs are often simulated by changes of land use/cover types to provide evidence for sustainable development of ecosystems (Grafius et al., 2016; Liu et al., 2018; Wu, 2013). For example, Jra et al. (2013) assessed trade-offs and synergies between water quality regulation and 10 other ecosystem services in the Australian Great Barrier Reef considering four different land use scenarios. Zank et al. (2016) simulated the effects of two alternative land use change development scenarios on natural capital stocks and ecosystem service flows in the Puget Sound region of Washington State. Groot et al. (2018) proposed the Landscape IMAGES modeling framework for multi-scale spatially explicit analysis of ecosystem services trade-offs and synergies across agricultural landscapes. Therefore, the land use change scenario analysis can help to reveal the trade-off relationship of ecosystem services.

China's Grain-for-Green Program (GFGP) is globally one of the most important ecological engineering projects in the context of ecological restoration and conservation, given the fact that it involves the largest investment and has the highest participation degree (Bryan et al., 2018; Rozelle, 2005; Wu et al., 2018). The implementation of the GFGP has introduced remarkable changes in land use patterns, which have altered the provisioning of various ecosystem services to a large extent (Xu et al., 2018). Studies have shown that the implementation of returning farmland to forest land has improved ecosystem regulation services and improved the quality of local eco-environment 

the implementation of the GFGP, the trade-off relationship between provisioning service and regulating service will become more and more obvious (Liu et al., 2014; Jia et al., 2014). Therefore, due to the complexity in trade-off relationships among multiple ecosystem services, the comprehensive benefits of GFGP are yet not well understood. It is necessary to compare different GFGP scenarios to analyze the influence of GFGP intensity on ecosystem services trade-offs, and thus to make suggestions for the optimal GFGP intensity.

As a typical ecological fragile area in the northwestern part of Yunnan Province, China, Dali Autonomous Prefecture is located in the transitional zone in-between the Yunnan Plateau and Qinghai-Tibet Plateau. This area is characterized by one of the highest richness in biodiversity and ethnic-cultural diversity globally. The rich natural and cultural landscapes make it an internationally renowned tourist destination. The large-scale tourism development in the past two decades has not only resulted in an extensive economic growth, but also lead to a significant increase in human activities, posing a great threat to the ecological fragile zone. Dali Autonomous Prefecture has implemented the GFGP since 2000, and land use/cover has also undergone dramatic changes in the past years. How to scientifically choose the implementation intensity of the GFGP has become a key issue. Therefore, taking Dali Autonomous Prefecture as a case study area, the study aims at the following detailed objectives: (1) to map land use change by setting different GFGP scenarios; (2) to quantify the impact of GFGP scenarios on four ecosystem services (i.e. carbon storage, soil conservation, water yield, and food production); and (3) to determine the optimal GFGP intensity based on ecosystem services trade-offs. 


\section{Material and method}

\subsection{Study area and data source}

The total area of Dali Autonomous Prefecture is $29,459 \mathrm{~km}^{2}$, of which the mountainous area accounts for more than 93\% (Figure 1). Situated within Yunnan Province $\left(98^{\circ} 52^{\prime}-101^{\circ} 03^{\prime} \mathrm{E}\right.$, and $\left.24^{\circ} 41^{\prime}-26^{\circ} 42^{\prime} \mathrm{N}\right)$, it has jurisdiction over Dali City and 11 counties. The climate is low-latitude plateau monsoon, characterized by distinctive dry and wet seasons as well as rainy and hot seasons. The annual average rainfall is between $800 \mathrm{~mm}$ and $1000 \mathrm{~mm}$, whereas the average annual average temperature is $15^{\circ} \mathrm{C}$. As a consequence the vegetation distribution is characterized by a clear vertical gradient.

The basic data used in this study includes: (1) GlobeLand30 data in 2000 and 2010, covering 10 types of surface cover (i.e. farmland, forest land, grass land, shrub land, wetland, water body, tundra, construction land, bare land, and glacier and permanent snow). According to the actual land use settings in Dali Autonomous Prefecture, the surface cover types are classified into the following six categories: farmland, forest land, grass land, shrub land, water body, and construction land (http://www.globallandcover.com/GLC30Download/index.aspx). This classification facilitated the quantitative evaluation of ecosystem services. (2) Digital elevation model with a resolution of $30 \mathrm{~m}$ was used to compute the terrain factors as used to run the RUSLE model (http://www.gscloud.cn/). (3) Meteorological data (i.e. temperature and precipitation) covering the period 1981 - 2010 were obtained from the national meteorological stations network of the Chinese Meteorological Science Data Sharing Service System (http://cdc.cma.gov.cn/home.do). More precisely, in this study the meteorological stations within and around the study area were considered in order to map spatial distribution of soil conservation and water yield. (4) Food production 
statistics and economic statistics of Dali Autonomous Prefecture were derived from the Yearbook of Dali Autonomous Prefecture covering the study period(Dali Bureau of Statistics, 2000, 2010). (5) The soil type map of Dali Autonomous Prefecture, extracted from the 1:1,000,000 soil database of China, was used to measure soil conservation and water yield. (6) The Vegetation Index was derived from the MOD13Q1 database of the Vegetation Index product synthesized by the MVC Method 16d and downloaded from the NASA MODIS website (http://modis.gsfc.nasa.gov/) with a spatial resolution of $250 \mathrm{~m}$.

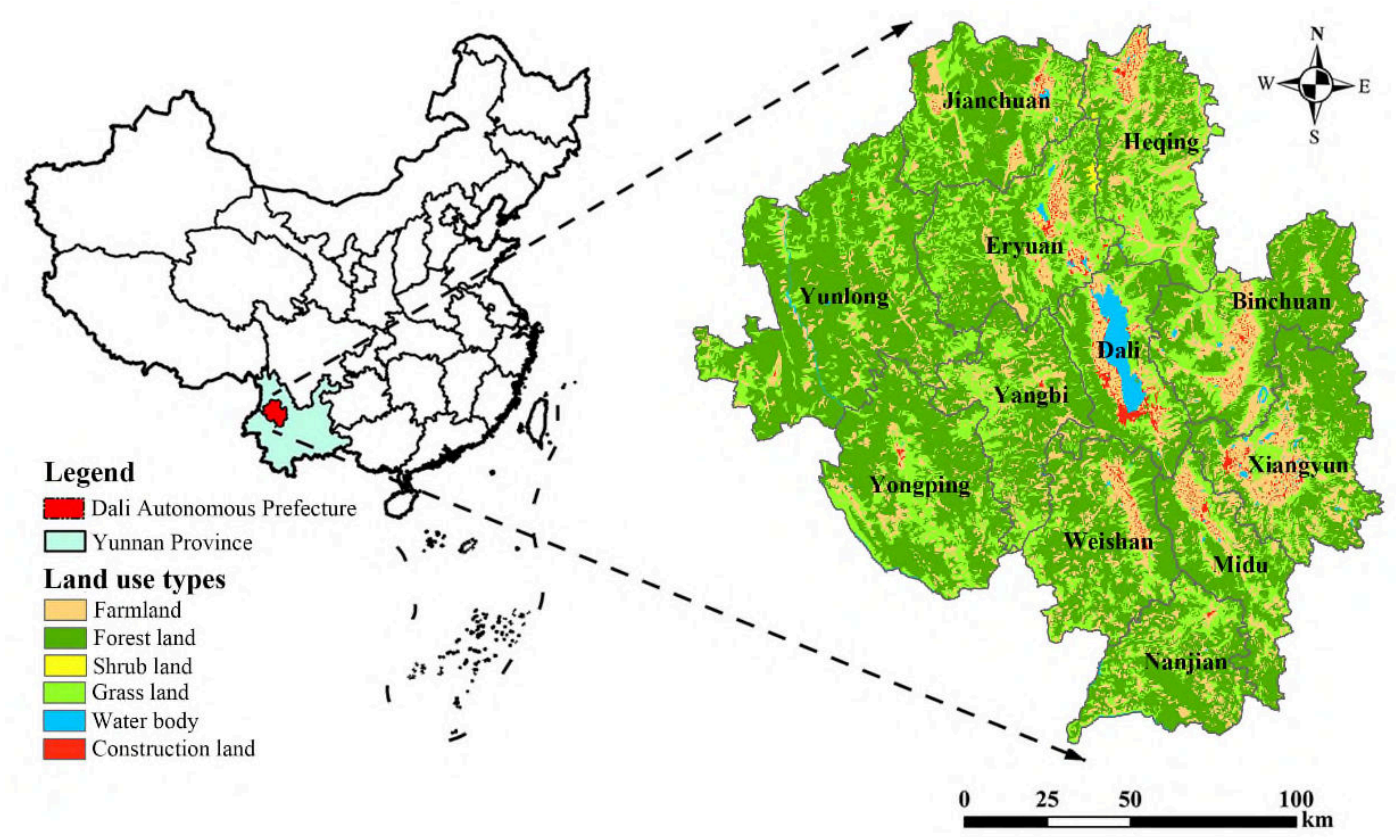

Figure 1 Geographical location and land use types of the study area

\subsection{Quantifying ecosystem services}

\subsubsection{Carbon storage}

In recent years, the InVEST model (The integration valuation of ecosystem services and trade-offs tool) is widely used for assessing and mapping ecosystem services (Arkema et al., 2015; He et al., 2016; Sharps et al., 2017). The carbon storage capacity of the study area has been analyzed based on the Carbon Storage and 
Sequestration module of the InVEST model. This module is generally composed of two parts, i.e. carbon storage in plants (including underground (roots) and aboveground (shoots) parts of plants), and carbon storage in the soil. In essence, it analyzes four major potential carbon sinks in the terrestrial sphere, i.e. (1) aboveground biomass (all living plant bodies); (2) root biomass (all the root systems of the aboveground biomass); (3) soil organic carbon (all carbon pools of the organic matter present in the soil); and (4) humus carbon: dead organic carbon stored in litter and deadwood.

$$
C_{\text {total }}=C_{\text {above }}+C_{\text {below }}+C_{\text {soil }}+C_{\text {dead }}
$$

In the formula, $C_{\text {total }}, C_{\text {above }}, C_{\text {below }}, C_{\text {soil }}$ and $C_{\text {dead }}$ represent total carbon $\left(\mathrm{t} / \mathrm{hm}^{2}\right)$, aboveground biomass $\left(\mathrm{t} / \mathrm{hm}^{2}\right)$, root biomass $\left(\mathrm{t} / \mathrm{hm} \mathrm{m}^{2}\right)$, soil organic carbon $\left(\mathrm{t} / \mathrm{hm}^{2}\right)$, and humus carbon $\left(\mathrm{t} / \mathrm{hm}^{2}\right)$, respectively.

The organic carbon stock data for the 4 pools comes from the Intergovernmental Panel on Climate Change (IPCC), covering various land use types such as farmland, forest land, and grassland. The storage density for other land use types are set according to the climatic factors of the study area (Newell et al., 2012).

\subsubsection{Soil conservation}

In this study, the RUSLE (Revised Universal Soil Loss Equation) model was used to determine the spatial pattern of soil erosion and soil conservation (Renard et al., 1991). More precisely, the soil conservation was calculated by subtracting the actual soil erosion from the potential soil erosion.

The potential and actual soil erosion as well as soil conservation are measured as follows:

$$
\begin{gathered}
A_{p}=R \times K \times L S \\
A_{r}=R \times K \times L S \times C \times P
\end{gathered}
$$




$$
\Delta A=A_{p}-A_{r}
$$

In the formula, $A_{p}, A_{r}$ and $\Delta A$ are the potential and actual soil erosion, and the soil conservation (ton $\left.\cdot \mathrm{ha}^{-2} \cdot \mathrm{a}^{-1}\right), R$ is the rainfall-runoff erosivity factor $\left(\mathrm{MJ} \cdot \mathrm{mm} \cdot \mathrm{hm}^{-1} \cdot \mathrm{h}^{-}\right.$ $\left.{ }^{1} \cdot \mathrm{a}^{-1}\right) ; K$ refers to the soil erodibility factor (ton $\cdot$ ha $\cdot \mathrm{MJ}^{-1} \cdot \mathrm{mm}^{-1}$ ); $L S$ is the slope length and steepness factor (dimensionless); $C$ is the coverage and management factor (dimensionless); and $P$ is the supporting practice factor.

\subsubsection{Water yield}

Water yield is an important freshwater related service of ecosystems. The InVEST Water Yield Module is based on the principle of basic water balance that considers three components: surface runoff, soil moisture, water holding capacity of litter and canopy interception. The Budyko curve and average annual rainfall are used to calculate water yield as follows (Zhang et al., 2001):

$$
Y_{x j}=\left(1-A E T_{x j} / P_{x}\right) \times P_{x}
$$

In the formula, $A E T_{x j}$ is the actual evapotranspiration for land cover type $j$ at pixel $x ; P_{x}$ is the annual precipitation at pixel $x$. The evapotranspiration is similar to the Budyko curve proposed by Zhang et al. (2001):

$$
A E T_{x j} / P_{x}=\left(1+w_{x} R_{x j}\right) /\left(1+w_{x} R_{x j}+1 / R_{x j}\right)
$$

In the formula, $R_{x j}$ is the aridity index for land cover type $j$ at pixel $x$, and the $w_{x}$ is the available water content of the vegetation at pixel $x$.

\subsubsection{Food production}

Yearly statistical data has been used to calculate the food production of farmland for each county. Subsequently a time synthesis method was used to reconstruct the NDVI time series from which the maximum value of $N D V I$, representing the best 
condition of vegetation growth within a given period of time, could be extracted rather easily. More precisely, a multi-layer / multi-temporal NDVI raster map was used from which for each pixel the maximum value was extracted using following formula:

$$
N D V I_{i}=M A X_{j=1}^{j=n} N D V I_{i . j}
$$

In this study, according to the internal normalized deference vegetation index of farmland for each county, the food production value was spatially downscaled from the county level to the pixel level using following formula:

$$
G_{i j}=N D V I_{i j} / N D V I_{\text {mean }, j} \times G_{j}
$$

In this formula, $i$ represents the $i^{\text {th }}$ grid of the farmland layer in the $j$ County, $G_{i j}$ indicates food production allocated by the $i$ grid of farmland in the $j$ County, $G_{j}$ indicates the food production of farmland in the $j$ County, $N D V I_{i j}$ indicates the NDVI of the $i$ farmland grid in the $j$ County, and $N D V I_{\text {mean,j }}$ represents the average value of farmland NDVI in the $j$ County. These processes were mainly realized in ArcGIS 10.2 using the software of Raster Calculator and Spatial Analysis tools.

\subsection{Simulating land use change based on CLUE-S model}

In this study, the CLUE-S model was used to simulate land use patterns in 2030, which is an improved version of the CLUE model (Conversion of Land Use and Its Effects) (Verburg et al., 2002). Spatial policy, conversion rules between land use types, land use requirements and spatial characteristics are required input data, in order to run the CLUE-S model. Spatial policies are regulations or restrictions formulated by the government or decision-maker who determines land use planning, and thus, will affect the occurrence of various land use changes. Restricted areas are areas where the land use type cannot be changed, for example key importance areas for ecological protection or food production, such as nature reserves and high productive farmlands. The land 
use type conversion rules mainly refer to the setting of the conversion elasticity for land use, including the setting of land use conversion flexibility and the setting of land use conversion order, which is necessary to repeatedly debug when carrying-out the actual model simulation process. Furthermore, land use needs measurement was performed to determine the annual rate of each change type. Finally, Gray model and Markov chain models were used to map the probability on the occurrence of each land use type. The total probability of a given land use type within specific region is calculated by applying a two-value logistic regression as follows:

$$
\log \left(P_{i} /\left(1-P_{i}\right)\right)=\beta_{0}+\beta_{1} X_{1, i}+\beta_{2} X_{2, i} \ldots+\beta_{n} X_{n, i}
$$

In the formula, $P_{i}$ is the probability of occurrence of a given land use type in the grid $i, X$ is the value of a given influencing factor on the grid $i$, and $\beta$ is the regression coefficient of each influence factor. Stepwise regression method is usually selected, with the ROC curve for significance test.

Four GFGP scenarios were set up based on the implementation intensity of GFGP. In the process of scenario setting, the "Notice on Accelerating the Implementation of the New Round of GFGP”, “A New Plan for GFGP in Yunnan Province”, and official documents such as land remediation planning from each counties were considered in order to ensure that all land use configurations in each scenario are possible result of the expected social development or land use management. In this study, 2030 was selected as the target year, and four scenarios focusing on GFGP and characterized as future land use patterns were set as follows: (1) natural GFGP scenario, follow the same natural trends of land use change in Dali Autonomous Prefecture as that during 20002010; (2) mild GFGP scenario, convert farmland on all slopes steeper than $25^{\circ}$ into forest land; (3) moderate GFGP scenario, convert farmland on all slope steeper than $20^{\circ}$ into forest land; and (4) strong GFGP scenario, convert farmland on all slope steeper 
than $15^{\circ}$ into forest land.

\section{Results}

\subsection{Land use change scenarios}

From the overall trend, Figure 2 shows the land use patterns under all four GFGP scenarios. The area of construction land in Dali Autonomous Prefecture will increase over time. The farmland around Erhai Lake have been occupied by human settlements, with gradually reducing. Due to the difference in the implementation intensity of GFGP, there are great differences in the area of farmland and forest land between the four scenarios.

From the perspective of scenarios comparison, in natural GFGP scenario, by 2030, land use demand in Dali Autonomous Prefecture will continue to change at a constant rate, while changes of farmland and forest land are particularly significant. Farmland will continue to decrease, mainly converted into forest land and shrub land. Forest land will increase with 30,632 ha, mainly resulting from the conversion of farmland, grass land and shrub land. Whereas, construction land will increase with 14,490ha, including the conversions from farmland, water body and grass land. Grass land and water body will be characterized by an obvious decrease of 23,971.5ha and 9,648ha, respectively. Shrub land will increase slightly with 391.5ha.

In all four GFGP scenarios, the counties with large areas of farmland transferred to forestland and grassland are Yongping County, Yunlong County, Xiangyun County, Binchuan County, and Heqing County, with steep slope for a large area proportion. In comparison with 2010, the area of farmland decreased with 25,587ha, 91,422ha, 21,6508.5ha, respectively for the mild, moderate, and strong GFGP scenarios (Table 1).

In all four GFGP scenarios, the reduction of farmland results in an increase in 
forest land and shrub land. Under the natural GFGP scenario, 3.40\% of farmland was converted into forest land, whereas under the moderate and strong GFGP scenario $10.90 \%$ and $26.13 \%$ of farmland were converted into forest land, respectively.

Table 1 Changes of farmland area under different GFGP scenarios

\begin{tabular}{cccc}
\hline GFGP scenarios & 2010 (ha) & 2030 (ha) & $\begin{array}{c}\text { Proportion of } \\
\text { reduced area (\%) }\end{array}$ \\
\hline Natural GFGP & 634961.25 & 623067.75 & $1.87 \%$ \\
Mild GFGP & 634961.25 & 609374.25 & $4.03 \%$ \\
Moderate GFGP & 634961.25 & 543539.25 & $14.40 \%$ \\
Strong GFGP & 634961.25 & 418452.75 & $34.10 \%$ \\
\hline
\end{tabular}

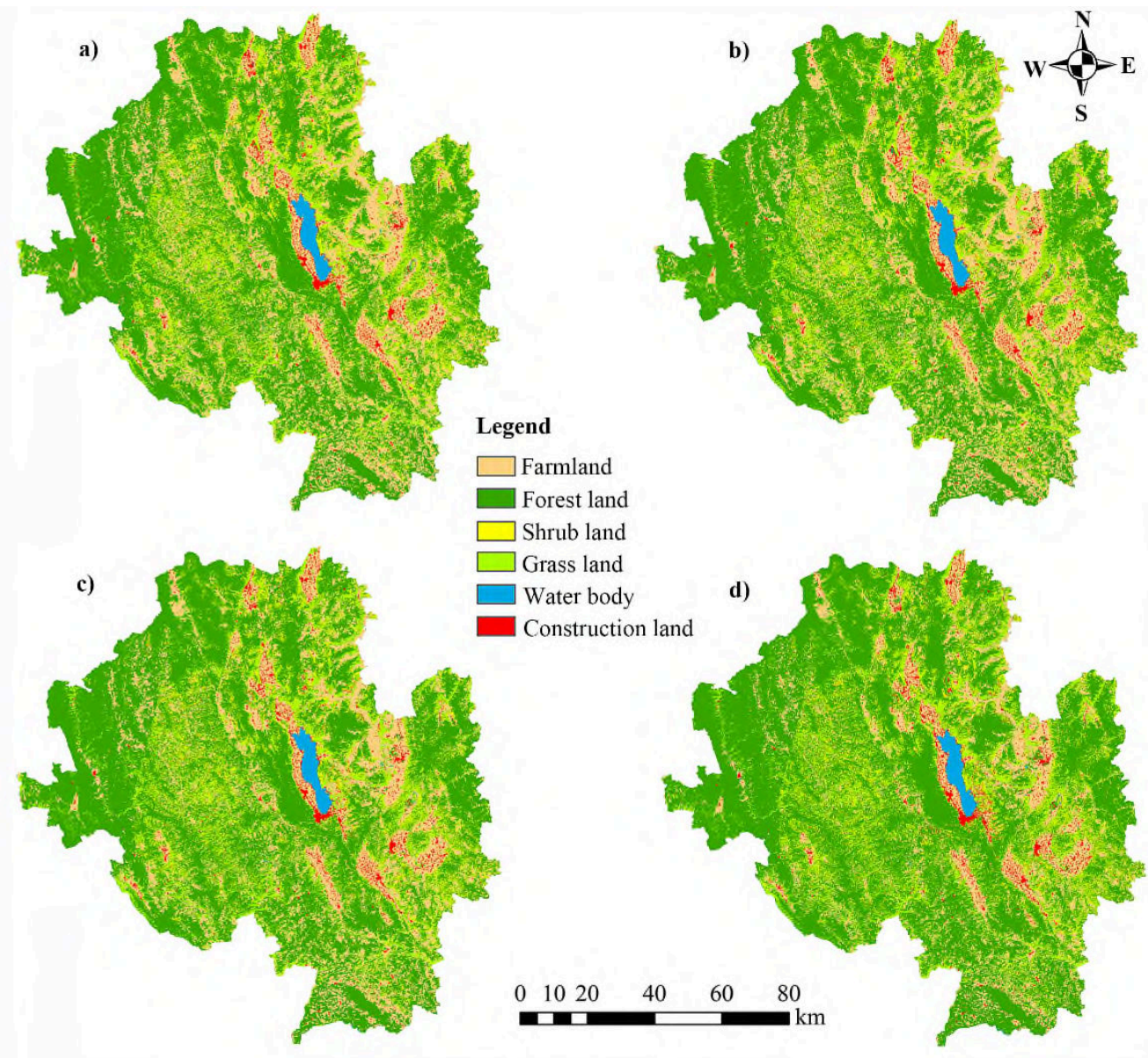

Figure 2. Land use patterns in 2030 under different Grain-for-Green Programme (GFGP) scenarios: a) natural GFGP; b) mild GFGP; c) moderate GFGP; d) strong GFGP 


\subsection{Ecosystem services change estimation}

Figure 3 shows the ecosystem services under different GFGP scenarios as considered in this study. The carbon storage in the study area gradually increases with the implementation of GFGP. Compared with 2010, the total amount of carbon storage increased in four GFGP scenarios by $0.63 \%, 1.01 \%, 3.50 \%$ and $8.01 \%$ respectively. Although GFGP scenarios have changed, the county rankings of total carbon storage remained basically unchanged. In Yunlong County, Yongping County and Jianchuan County, all located in the west of Dali Autonomous Prefecture, the ecological resources are excellent. As the forest land coverage rate is high, the total carbon storage of these three counties is the highest. On the contrary, in Dali City, Midu County and Nanjian County the ecological resources are poor due to the wide distribution of farmland and high degree of urbanization. The vegetation coverage in these areas is relatively low, and thus the provision of carbon storage is weak.

Soil conservation is profoundly influenced by the vegetation growth and the land use/soil management practices. The areas with strong soil conservation are mainly distributed in areas with good vegetation coverage and flat terrain in Dali Autonomous Prefecture, while the areas such as mountains, slopes with poor vegetation coverage and relatively frequent human activities have weak provision of soil conservation. With increasing GFGP intensity, the total amount of soil conservation in the study area gradually increases. Compared with 2010 , the total amount of soil conservation increased by $0.28 \%, 0.36 \%, 0.82 \%$ and $1.57 \%$, respectively. Although GFGP scenario changed, the order of total soil conservation in the county remained basically unchanged. Yunlong County, Yongping County and Binchuan County have always been characterized by the highest soil conservation, with Dali City, Midu County and Nanzhang County for the lowest. 
With the continuous strengthening of GFGP, the total amount of water yield in the study area has increased firstly and then decreased. Compared with 2010, the amount of water yield in natural GFGP scenario increased by $0.01 \%$, while in the other three scenarios, water yield decreased by $0.02 \%, 0.26 \%$ and $0.70 \%$, respectively. The increase and decrease of water yield in the study area were all not significant. Although GFGP scenarios have changed, the county rankings of total water yield remained basically the same. The total amount of water yield in Yunlong County is significantly higher than that in other counties, together with Yongping County and Eryuan County for top three. The total amount of water yield in each county has a slight decrease with the increase of GFGP intensity. However, the reduction of water yield is the smallest in Dali City and Midu County under all four scenarios.

Food production in Dali Autonomous Prefecture has obvious spatial agglomeration characteristics. The high value area of food production is concentrated around the Erhai Lake and its western areas. These areas are flat, with large area of farmland, and good hydrothermal conditions. With the continuous strengthening of the GFGP intensity, the sharp decline in the area of farmland has led to a gradual reduction in the total amount of food production, resulting in high risk of local food security. Compared with 2010, the food production decreased by $2.23 \%, 4.31 \%, 14.10 \%$ and $33.13 \%$ respectively. Especially when the GFGP is implemented for the farmland on the slope from steeper than $20^{\circ}$ to $15^{\circ}$, the total food production of each county has declined mostly. In terms of total amount, Xiangyun County, Dali City and Eryuan County ranks for the highest food production, with the counties of Nanjian, Jianchuan and Yangbi for the lowest. 

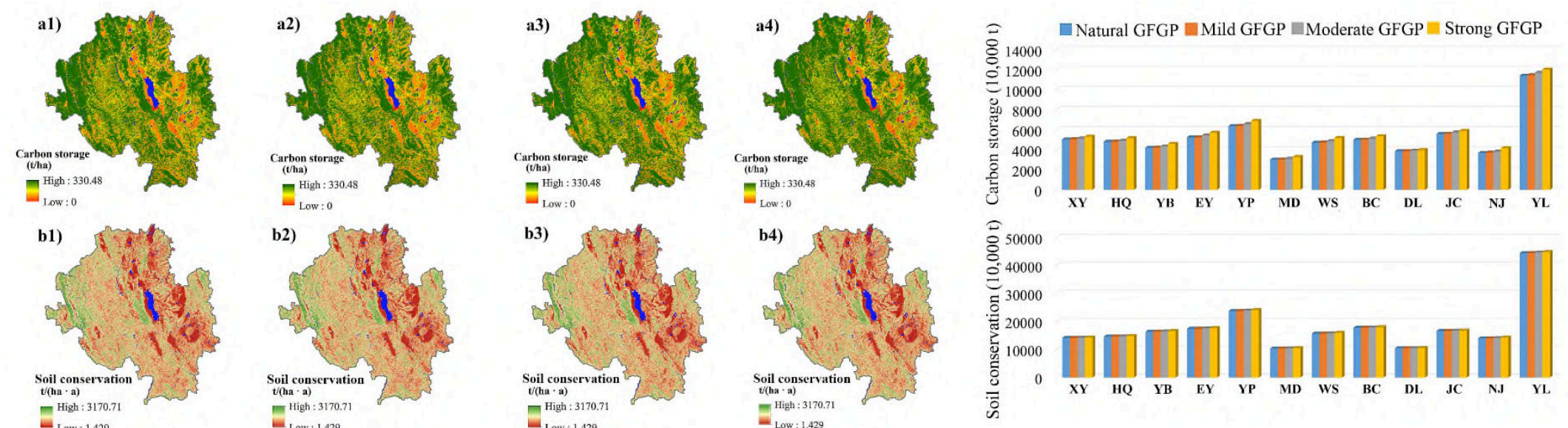

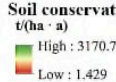

Soil conservatiti
Uha a a)
[High : 3170.71

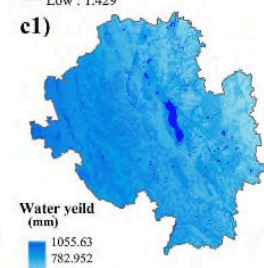

c2)

c3)

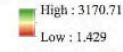

\&5 50000
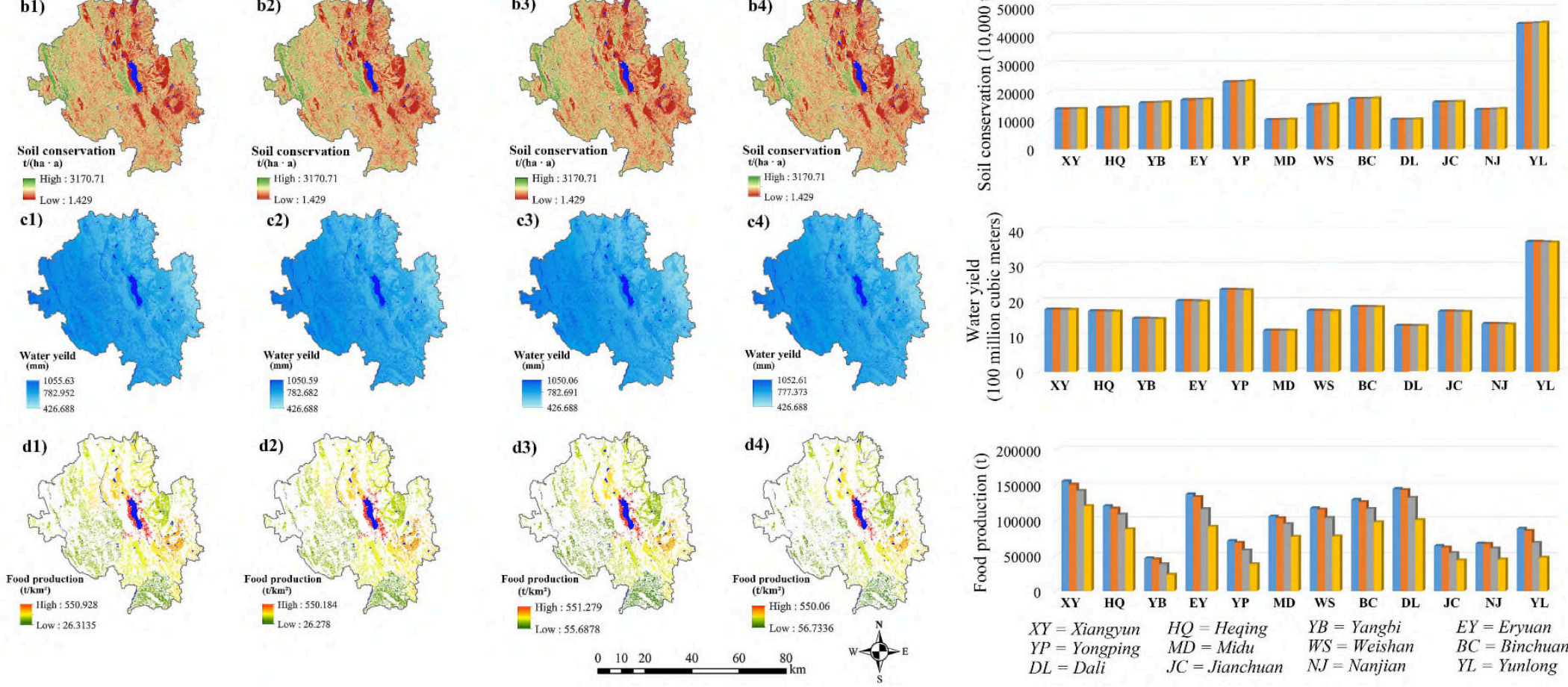

Figure 3. Ecosystem services in different Grain-for-Green Programme (GFGP) scenarios: a) natural GFGP; b) mild GFGP; c) moderate GFGP; d) strong GFGP 


\subsection{Ecosystem services trade-offs}

Based on the four ecosystem services scenarios analysis, the total amount of carbon storage, soil conservation, water yield and food production were calculated (Figure 4). Under the natural GFGP scenario, the total amount of carbon storage, soil conservation and water yield showed an increasing trend compared with 2010, with an increase of 3.95 million tons, 6.01 million tons and 0.03 billion $\mathrm{m}^{3}$ respectively, or relatively $0.63 \%$. $0.28 \%$ and $0.01 \%$. On the contrary, the total amount of food production showed a decreasing trend, which was reduced by about 28,000 tons and decreased by $2.23 \%$. Our results reveals that under the natural GFGP scenario, carbon storage, soil conservation and water yield increase in synergy, whereas food production and these three ecosystem services are characterized by a clear trade-off relationship.

Under the mild GFGP scenario, farmland in the Dali Prefecture decreased by about 25,587 ha, which resulted in a slight decrease in forest land. As compared with 2010, the total amount of carbon storage and soil conservation services increased, with 6.33 and 7.82 million tons, respectively (or $1.01 \%$ and $0.36 \%$ ). On the contrary, compared with 2010 , the amount of water yield showed a decreasing trend, i.e. 0.05 billion $\mathrm{m}^{3}$ or $0.02 \%$. At the same time, the overall food production decreased by 54,700 tons, which corresponds with $4.30 \%$. Moreover, these results show that under the mild GFGP scenario, carbon storage has a synergistic relationship with soil conservation, food production and water yield, whereas food production and carbon storage, food production and soil conservation, water yield and carbon storage, water yield and soil conservation are all characterized by trade-offs.

Under the moderate scenario, farmland in the Dali Prefecture decreased by about 91,422 ha, which resulted in a decrease of 179,000 tons or $14.1 \%$ of food production. 
Compared with 2010, carbon storage and soil conservation continued to increase, increasing by 21.86 million tons and 1.87 million tons respectively, with a slight increase of $3.49 \%$ and $0.82 \%$ respectively. Water yield was further reduced by 57 million cubic meters, or $0.26 \%$. Under this scenario, the correlation between various ecosystem services is consistent with mild GFGP scenario. In addition to a synergistic relationship between carbon storage and soil conservation, water yield and food production, all other ecosystem services maintain a tradeoff relationship.

Considering the strong GFGP scenario, farmland showed a great reduction of 214,508.5 ha, which led to a significant reduction in the total amount of food production, equal to $33.12 \%$. At the same time, water yield showed a reduction of 155 million $\mathrm{m}^{3}$ or $0.70 \%$. On the contrary, the total amount of carbon storage and soil conservation services were characterized by an increase of 50.1 million tons and 34.01 million tons, respectively, (i.e. $8.01 \%$ and $1.57 \%$ ). Hence, these results showed that carbon storage and soil conservation, food production and water yield are characterized by a synergistic relationship, while food production and carbon storage, food production and soil conservation, water yield and carbon storage, water yield and soil conservation still show trade-off relationship.

The ecosystem services simulation results across the different scenarios are standardized by Z-score in order to characterize trade-offs and synergies between different ecosystem services more clearly, as being shown by the ecosystem services trade-offs rose diagram in Figure 4. In the current status (2010) of ecosystem services, the level of food production and water yield is relatively high. On the contrary, the level of carbon storage and soil conservation is low. The supply services and regulation services of the entire study area characterized by an obvious trade-off relationship. Under natural GFGP scenario, soil conservation and carbon storage have been slightly 
improved, meanwhile, water yield and food production have all decreased slightly, despite being rather high. The contradiction between the supply services and the adjustment services is still severe. Under the mild GFGP scenario, ecosystem services trade-offs are very similar of that under the natural and mild GFGP scenario, i.e. food production and water yield are still at a high level, but which is slightly lower than that under the natural GFGP scenario. However, the increase in soil conservation and carbon storage are restricted, indicating that the overall ecological benefits of the GFGP will not be significant. Under the moderate GFGP scenario, food production, carbon storage and soil conservation are at a medium level, water yield is at the upper-middle level, and the ecological benefits of GFGP are clearly manifested. In addition, soil conservation and carbon storage have obvious advantages compared with other scenarios. However, food production and water yield are significantly reduced as regards the current status (2010). This indicates that the ecological benefits of the GFGP are threatening regional food security and water supply.

Overall, both carbon storage and soil conservation showed an increasing trend under all four scenarios, meanwhile, food production showed a decreasing trend. Except for a slight increase under the natural GFGP scenario, under which water yield is characterized by a decreasing trend. With the increase of GFGP's intensity, these four ecosystem services have changed more and more compared with 2010. In each scenario, the rate of change was consistent with that of 2010, with following order (from big to small): food production, carbon storage, soil conservation and water yield. This shows that the change of farmland intensity has the greatest influence on food production, and it fluctuates the most. However, the change of GFGP's intensity had the least effect on water yield, and its fluctuation was slightly smaller than other ecosystem services.

Carbon storage and soil conservation are synergistic in all four GFGP scenarios. 
Except for the synergy between carbon storage and soil conservation under the natural GFGP scenario, water yield shows a trade-off relationship with these two ecosystem services. Furthermore, food production and carbon storage, food production and soil conservation have trade-offs relationship in all four scenarios. This also shows that the contradiction between the supply services and the ecological regulation services is strongly determined by the management of ecosystem services in Dali, and therefore, requires great attention from decision makers.

a)

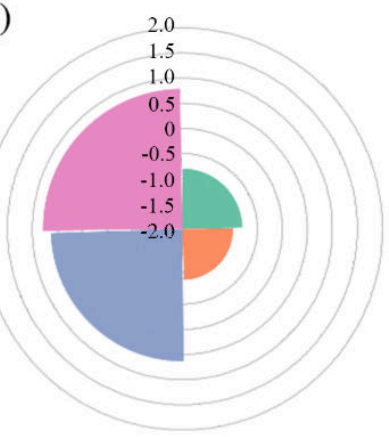

d)

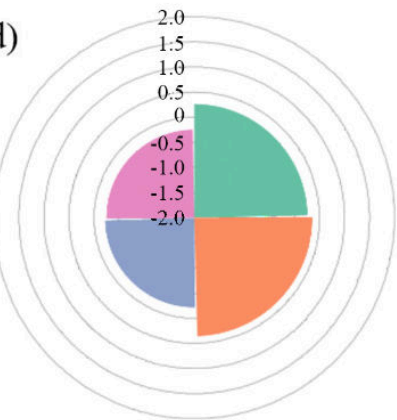

b)

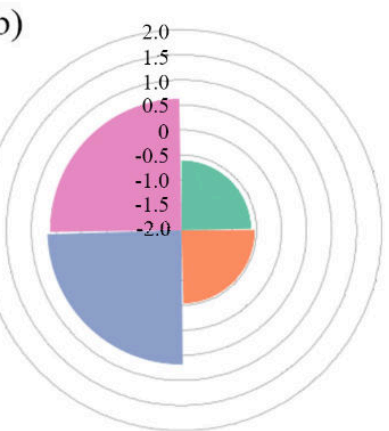

e)

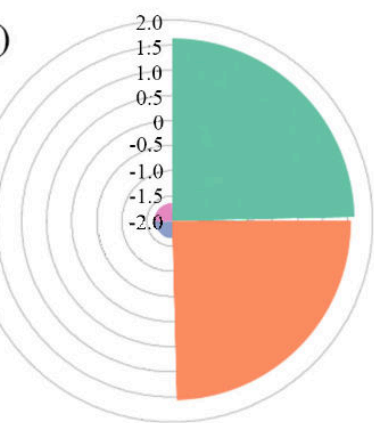

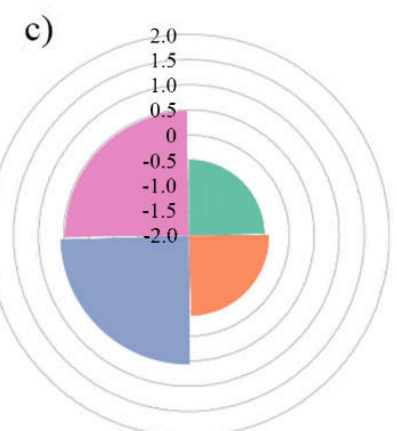

Ecosystem services

Carbon storage

Soil conservation

$\square$ Water yeild

$\square$ Food production

Figure 4. Ecosystem services trade-offs in different Grain-for-Green Programme (GFGP) scenarios: a) current status in 2010; b) natural GFGP; c) mild GFGP; d) moderate GFGP; e) strong GFGP.

\section{Discussions}

\subsection{Policy implications for GFGP}

GFGP has been an important measure to improve the human ecological environment since the 20th century (Bryan et al., 2018; Chen et al., 2009; Rozelle, 
2005). However, while significant ecological benefits have been generated, whether there are ecological-economic hidden dangers in the GFGP requires serious consideration by policy makers. Has the implementation of ecological engineering achieved a win-win situation for all types of ecosystem services? The result of this study shows that the contradiction between supply services and ecological regulation services runs through the ecosystem service management in Dali prefecture. The implementation of the GFGP will lead to improved carbon storage and soil conservation while reducing food production and water yield. The result of the current study on ecosystem services trade-offs was consistent with those in previous studies showing that the significant increase of vegetation surface cover in the GFGP areas lead to the increase of soil fertility, soil erosion, river sediment, and nutrient loss, and thus lead to the improvement of carbon storage and soil conservation (Jia et al., 2014; Wang et al., 2017). But at the same time, the implementation of the GFGP lead to the increase of the area of forest land, grassland, and other vegetative land use types. The evapotranspiration under forests is higher than that under other land cover types. Therefore, under the condition of consistent climatic conditions, water yield in the basin has declined with the expansion of forest land (Chisholm, 2010; Dijk \& Keenan, 2007). Meanwhile, the increase of soil infiltration delayed the time of precipitation confluence in the basin and reduced the peak discharge, so the water yield decreases ( $\mathrm{Hu}$, et al., 2015, Long et al., 2006, Xu et al., 2006). Ecological system management (EBM) should be devoted to GFGP policy formulation and implementation process in the future, comprehensively considering the tradeoff between ecosystem services, according to the regional ecological demand, and the characteristics of the geographical factors, formulate the corresponding ecological restoration target, range and method of ecological restoration, so as to realize the sustainable ecosystem services provided (Jia 
et al., 2014).

Scenario simulation is an important method to explore the impact of land use change on multiple ecosystem services driven by policy. The effects of GFGP's intensity on regional ecosystem services performance were simulated dynamically through scenario simulation to explore the implementation intensity of the GFGP to maximize the improvement of the regional ecological environment, and four scenarios of GFGP were considered, i.e. natural, mild, moderate and strong GFGP. Studies have showed that an excessive focus on optimizing the ecological benefits through GFGP would not only bring about improvement of carbon storage and soil conservation, but also endanger regional food security and water supply (Wang et al., 2017). While, under scenario of mild GFGP, the initiation of the GFGP to protect the environment and mitigate disasters cannot be realized (Jia et al., 2014; Wang et al., 2017). Therefore, finding a suitable GFGP intensity is of great significance for realizing the win-win situation of regional "resource demand" and "ecological demand". The differences between extreme scenarios were explored through natural GFGP scenario and strong GFGP scenario. Meanwhile, this study constructed mild GFGP scenario and moderate scenario to explore which scenario is more balanced with four kinds of ecosystem services. Rose chart of ecosystem services trade-offs can represent the trade-offs and synergies among multiple ecosystem services in different situations (Renard et al., 2015). Results show that the implementation of GFGP in Dali Prefecture will make that various ecosystem services in the region has another rate or direction of change. However, in general, the changes depend on the GFGP's intensity. Farmland with the slope steeper than $20^{\circ}$ is mostly non-basic farmland with low yield and difficult for cultivation, which is an important source of land degradation and soil erosion. Under the moderate GFGP scenario, characterized by the restriction on the implementation of 
farmland with the slope steeper than $20^{\circ}$, the supply levels of four kinds of ecosystem services are the most balanced. Food production is secured, and soil conservation as well as carbon storage are strengthened. Land use allocation under this scenario can help to achieve social development and ecological conservation simultaneously.

\subsection{Limitations and future research directions}

The CLUE-S model provides a dynamic, spatially defined model of land use change for regional scales through scenario analysis. The model's land use stability, which is specifically used to analyze small spatial resolutions (such as watersheds or provinces), consists of a set of variables that define the relative elasticity of the actual land use type and conversion. As a consequence, the user needs expert knowledge or survey data to specify these settings. The CLUE-S model is very sensitive to the conversion of rule settings, and the parameter settings need to be carefully considered. In order to better combine the results of ecosystem services trade-offs with policies such as ecological compensation mechanisms in the process of ecosystem service scenario simulation, it is necessary not only to further refine the division of relevant stake holders, but also to fully understand the basis of the real needs of different groups, clarifying the objects, the content and the ultimate purpose of ecosystem services trade-offs, as well as presenting achievable and verifiable ecosystem service management and optimization solutions. Incorporating stake holders into the research process can further improve the quantitative identification and assessment level of ecosystem services, effectively avoiding the limitations of decision makers themselves.

This study is based on CLUE-S for land use change simulation. The simulation scenario setting focuses on the intensity difference of the GFGP, and sets up four scenarios, i.e. natural, mild, moderate and strong GFG. However, as the city is a 
complex and large system, and Dali Prefecture has experienced rapid growth in recent years, there is a large amount of uncertainty about the impact of human activities on land use. How to simulate the future more reasonably, and more in particular how to strengthen macro-factor research, such as multi-agent, human-computer interaction, game theory, will be key in order to have a greater flexibility on the scenarioparameterization, and therefore, will be the main focuses for future research.

\section{Conclusion}

This study simulate land use status of Dali Autonomous Prefecture in 2030 using the CLUE-S model by setting different scenarios of GFGP intensity to analyze the spatial pattern of ecosystem services trade-offs. In general, under the moderate GFGP scenario, the supply levels of carbon storage, soil conservation, water yield and food production are the most balanced. In addition to the substantial increase in carbon storage and soil conservation as a result of the GFGP implementation, the supply of water and food in the study area has not been greatly affected. Carbon storage and soil conservation are synergistic in all four scenarios. Except for the identified synergy with carbon storage and soil conservation under the natural GFGP scenario, water yield shows a trade-off relationship with these two ecosystem services across all other scenarios. Besides, under all four scenarios, food production and carbon storage, food production and soil conservation are all characterized by trade-off relationship. This illustrates that the contradiction between the supply services and the ecological regulation services runs through the management of ecosystem services in Dali Prefecture from beginning to end. In order to better combine the results of ecosystem services trade-offs with policies, it is necessary not only to further refine the division of relevant stake holders, but also to fully understand the basis of the real needs of different 
groups, effectively avoiding the limitations of decision makers themselves.

Acknowledgements: This research was financially supported by the National Natural Science Foundation of China (No. 41322004).

\section{References}

Albert, I.J.M.V.D., Rodney, J.K., 2007. Planted forests and water in perspective. For. Ecol. Manage. $251(1), 1-9$.

Arkema, K.K., Verutes, G.M., Wood, S.A., Clarke-Samuels, C., Rosado, S., Canto, M., Osenthal, A., Ruckelshaus, M., Guannel, G., Toft, J., Faries, J., Silver, J.M., Griffin, R., Guerry, A.D., 2015. Embedding ecosystem services in coastal planning leads to better outcomes for people and nature. Proc. Natl. Acad. Sci. U.S.A. 112 (24), 7390-7395.

Bryan, B.A., Gao, L., Ye, Y.Q., Sun, X.F., Connor, J.D., Crossman, N.D., Stafford-Smith, M., Wu, J.G., He, C.Y., Yu, D.Y., Liu, Z.F., Li, A., Huang, Q.X., Ren, H., Deng, X.Z., Zheng, H., Niu, J.M., Han, G.D., Hou, X.Y., 2018. China's response to a national land-system sustainability emergency. Nature. 559 (7713), 193-204.

Chen, X.D., Lupi, F., He, G.M., Ouyang, Z.Y., Liu, J.G., 2009. Factors affecting land reconversion plans following a payment for ecosystem service program. Biol. Conserv. 142 (8), 1740-1747.

Chisholm, R.A., 2010. Trade-offs between ecosystem services: water and carbon in a biodiversity hotspot. Ecol. Econ. 69 (10), 1973-1987.

Costanza, R., d'Arge, R., Groot, R.D., Farber, S., Grasso, M., Hannon, B., Limburg, K., Naeem, S., O'Neill, R.V., Paruelo, J., Raskin, R.G., Sutton, P., van den Belt, M., 1997. The value of the world's ecosystem services and natural capital. Nature. 387 (1), 3-15.

Costanza, R., Groot, R.D., Braat, L., Kubiszewski, I., Fioramonti, L., Sutton, P., Farber S., Grasso M., 2017. Twenty years of ecosystem services: how far have we come and how far do we still need to go? Ecosyst. Serv. 28, 1-16.

Dali Bureau of Statistics, 2000. Dali Statistic Yearbook. China Statistics Press, Beijing. 
Dali Bureau of Statistics, 2010. Dali Statistic Yearbook. China Statistics Press, Beijing.

Deng, L., Shangguan, Z.P., Rui, L.I., 2012. Effects of the grain-for-green program on soil erosion in China. Int. J. Sediment Res. 27 (1), 120-127.

Divinsky, I., Becker, N., Bar, P., 2017. Ecosystem service tradeoff between grazing intensity and other services-a case study in Karei-Deshe experimental cattle range in northern Israel. Ecosyst. Serv. 24, 16-27.

Geneletti, D., 2013. Assessing the impact of alternative land-use zoning policies on future ecosystem services. Environ. Impact Assess. Rev. 40 (1), 25-35.

Goldstein, J.H., Caldarone, G., Duarte, T.K., Ennaanay, D., Hannahs, N., Mendoza, G., Polasky, S., Wolny, S., Daily, G.C., 2012. Integrating ecosystem-service tradeoffs into land-use decisions. Proc. Natl. Acad. Sci. U.S.A. 109 (19), 7565-7570.

Grafius, D.R., Corstanje, R., Warren, P.H., Evans, K.L., Hancock, S., Harris, J.A., 2016. The impact of land use/land cover scale on modelling urban ecosystem services. Landsc. Ecol. 31 (7), 1509-1522.

Groot, J.C.J., Yalew, S.G., Rossing, W.A.H., 2018. Exploring ecosystem services trade-offs in agricultural landscapes with a multi-objective programming approach. Landsc. Urban Plan. $172,29-36$.

Dali Bureau of Statistics, 2015. Dili Statistic Yearbook. China Statistics Press, Beijing.

Halecki, W., Kruk, E., Ryczek, M., 2018. Loss of topsoil and soil erosion by water in agricultural areas: A multi-criteria approach for various land use scenarios in the Western Carpathians using a SWAT model. Land Use Pol. 73, 363-372.

Hao, R., Yu, D., 2018. Optimization schemes for grass land ecosystem services under climate change. Ecol. Indic. 85, 1158-1169.

He, C., Zhang, D., Huang, Q., Zhao, Y., 2016. Assessing the potential impacts of urban expansion on regional carbon storage by linking the LUSD-urban and InVEST models. Environ. Modell. Softw. 75, 44-58.

Hu, H., Fu, B., Lv, Y., Zheng, Z., 2015. SAORES: a spatially explicit assessment and optimization tool for regional ecosystem services. Landsc. Ecol. 30 (3), 547-560. 
Hu, Y., Peng, J., Liu, Y., Tian, L., 2018. Integrating ecosystem services trade-offs with paddy landto-dry land decisions: A scenario approach in Erhai Lake Basin, southwest China. Sci. Total Environ. 625, 849.

Jia, X., Fu, B., Feng, X., Hou, G., Liu, Y., Wang, X., 2014. The tradeoff and synergy between ecosystem services in the Grain-for-Green areas in Northern Shaanxi, China. Ecol. Indic. 43 (1), 103-113.

Jra, B., Wong, G.Y., Metcalfe, D.J., Honzák, M., Pert, P.L., Rao, N., Grieken, M.E.V., Lawson, T., Bruce, C., Kroon, F.J., Brodie, J.E., 2013. An analysis of trade-offs between multiple ecosystem services and stakeholders linked to land use and water quality management in the Great Barrier Reef, Australia. Agric. Ecosyst. Environ. 180 (6), 176-191.

Kerschbaumer, L., Köbbing, J.F., Ott, K., Zerbe, S., Thevs, N., 2015. Development scenarios on hetao irrigation area (China): a qualitative analysis from social, economic and ecological perspectives. Environ. Earth Sci. 73 (2), 815-834.

Konarska, K.M., Sutton, P.C., Castellon, M., 2004. Evaluating scale dependence of ecosystem service valuation: a comparison of NOAA-AVHRR and Landsat TM datasets. Ecol. Econ. 41 (3), 491-507.

Lafortezza, R., Chen, J., 2016. The provision of ecosystem services in response to global change: evidences and applications. Environ. Res. 147, 576.

Li, Y., Zhang, L., Qiu, J., Yan, J., Wan, L., Wang, P., Hu, N., Cheng, W., Fu, B., 2017. Spatially explicit quantification of the interactions among ecosystem services. Landsc. Ecol. 32 (6), 1181-1199.

Liu, D., Chen, Y., Cai, W., Dong, W., Xiao, J., Chen, J., Zhang, H.C., Xia, J.Z., Yuan, W.P., 2014. The contribution of china's grain to green program to carbon sequestration. Landsc. Ecol. 29 (10), 1675-1688.

Liu, D., Zheng, X., Wang, H., Zhang, C., Li, J., Lv, Y., 2018. Interoperable scenario simulation of land-use policy for Beijing-Tianjin-Hebei region, China. Land Use Pol. 75, 155-165.

Liu, X., Liang, X., Li, X., Xu, X., Ou, J., Chen, Y., Li, S.Y., Wang, S.J., Pei, F.S., 2017. A future land use simulation model (FLUS) for simulating multiple land use scenarios by coupling human and natural effects. Landsc. Urban Plan. 168, 94-116. 
Long, H.L., Heilig, G.K., Wang, J., Li, X.B., Luo, M., Wu, X.Q., Zhang, M., 2006. Land use and soil erosion in the upper reaches of the Yangtze River: Some socio-economic considerations on China's Grain-for-Green Programme. Land Degrad. Dev. 17 (6): 589-603.

Newell, J.P., Vos, R.O., 2012. Accounting for forest carbon pool dynamics in product carbon footprints: Challenges and opportunities. Environ. Impact Assess. Rev. 37, 23-36.

Renard, D., Rhemtulla, J. M., Bennett, E. M., 2015. Historical dynamics in ecosystem service bundles. Proc. Natl. Acad. Sci. U. S. A. 112(43), 13411-13416.

Renard, K.G., Foster, G.R.,Weesies, G.A., Porter, J.P., 1991. RUSLE: revised universal soil loss equation. J. Soil Water Conserv. 46, 30-33.

Rodríguez, J.P., Beard, T.D., Bennett, E.M., Cumming, G.S., Cork, S.J., Agard, J., Dobson, A.P., Peterson, G.D., 2006. Trade-offs across space, time, and ecosystem services. Ecol. Soc. 11 (1), 709-723.

Rozelle, S., 2005. Grain for Green: Cost-Effectiveness and Sustainability of China's Conservation Set-Aside Program. Land Econ. 81 (2), 247-264.

Sandhu, H., Clarke, B., Baring, R., Anderson, S., Fisk, C., Dittmann, S., Walker S, Sutton P., Kubiszewski, I., Costanza, R., 2018. Scenario planning including ecosystem services for a coastal region in south Australia. Ecosyst. Serv. 31, 194-207.

Scholte, S.S.K., Daams, M., Farjon, H., Sijtsma, F.J., Teeffelen, A.J.A.V., Verburg, P.H., 2018. Mapping recreation as an ecosystem service: considering scale, interregional differences and the influence of physical attributes. Landsc. Urban Plan. 175, 149-160.

Sharps, K., Masante, D., Thomas, A., Jackson, B., Redhead, J., May, L., Prosser, H., Cosby, B., Emmett, B., Jones, L., 2017. Comparing strengths and weaknesses of three ecosystem services modelling tools in a diverse UK river catchment. Sci. Total Environ. 584-585, 118-130.

Tolessa, T., Senbeta, F., Kidane, M., 2017. The impact of land use/land cover change on ecosystem services in the central highlands of Ethiopia. Ecosyst. Serv. 23, 47-54.

Verburg, P.H., Soepboer, W., Veldkamp, A., Limpiada, R., Espaldon, V., Mastura, S.S., 2002. Modeling the spatial dynamics of regional land use: the clue-s model. Environ. Manage. 30 (3), 391-405.

Wang, J., Peng, J., Zhao, M., Liu, Y., Chen, Y., 2017. Significant trade-offs for the impact of Grain- 
for-Green Programme on ecosystem services in North-western Yunnan, China. Sci. Total Environ. 574, 57-64.

Wu, J., 2013. Landscape sustainability science: ecosystem services and human well-being in changing landscapes. Landsc. Ecol. 28 (6), 999-1023.

Wu, X., Wang, S., Fu, B., Liu, Y., Zhu, Y., 2018. Land use optimization based on ecosystem service assessment: A case study in the Yanhe watershed. Land Use Pol. 72 (1), 303-312.

Xu, J., Yin, R., Li, Z., Liu, C., 2006. China's ecological rehabilitation: unprecedented efforts, dramatic impacts, and requisite policies. Ecol. Econ. 57 (4), 595-607.

Xu, Z.H., Wei, H.J., Fan, W.G., Wang, X.C., Huang, B.L., Lu, N.C., Ren, J.H., Dong, X.B., 2018. Energy modeling simulation of changes in ecosystem services before and after the implementation of a Grain-for-Green program on the Loess Plateau-A case study of the Zhifanggou valley in Ansai County, Shaanxi Province, China. Ecosyst. Serv. 31, 32-43.

Xu, Z.H., Fan, W.G., Wei, H.J., Zhang, P., Ren, J.H., Gao, Z.C., Ulgiati, S., Kong, W.D., D, X.B., 2019. Evaluation and simulation of the impact of land use change on ecosystem services based on a carbon flow model: A case study of the Manas River Basin of Xinjiang, China. Sci. Total Environ. 652, 117-133.

Yi, H., Güneralp, B., Kreuter, U.P., Güneralp, İ., Filippi, A.M., 2018. Spatial and temporal changes in biodiversity and ecosystem services in the San Antonio River Basin, Texas, from 1984 to 2010. Sci. Total Environ. 619-620, 1259.

Zank, B., Bagstad, K.J., Voigt, B., Villa, F., 2016. Modeling the effects of urban expansion on natural capital stocks and ecosystem service flows: A case study in the Puget Sound, Washington, USA. Landsc. Urban Plan. 149, 31-42.

Zhang, L., Dawes, W.R., Walker, G.R., 2001. Response of mean annual evapotranspiration to vegetation changes at catchment scale. Water Resour. Res. 37 (3), 701-708. 